\title{
Familial aneurysms of the interventricular septum
}

Ming-Ren Chen, Michael L Rigby, Andrew N Redington

\begin{abstract}
Congenital aneurysms of the interventricular septum were found in a 29 year old man and his four year old son. Both were symptom free. In both, $M$ mode and cross sectional echocardiography showed an aneurysm in the mid-muscular trabecular portion of the ventricular septum with considerable paradoxical motion of the aneurysmal segment. Otherwise the chamber dimensions, intracardiac structures, and cardiac function were normal for age.

Congenital aneurysm of the interventricular septum is rare and these familial cases may be unique.
\end{abstract}

Most left ventricular aneurysms occur in adults and are related to coronary occlusion and myocardial ischaemia. In childhood the acquired causes of left ventricular aneurysm include anomalous origin of the left coronary artery from the pulmonary artery, transient
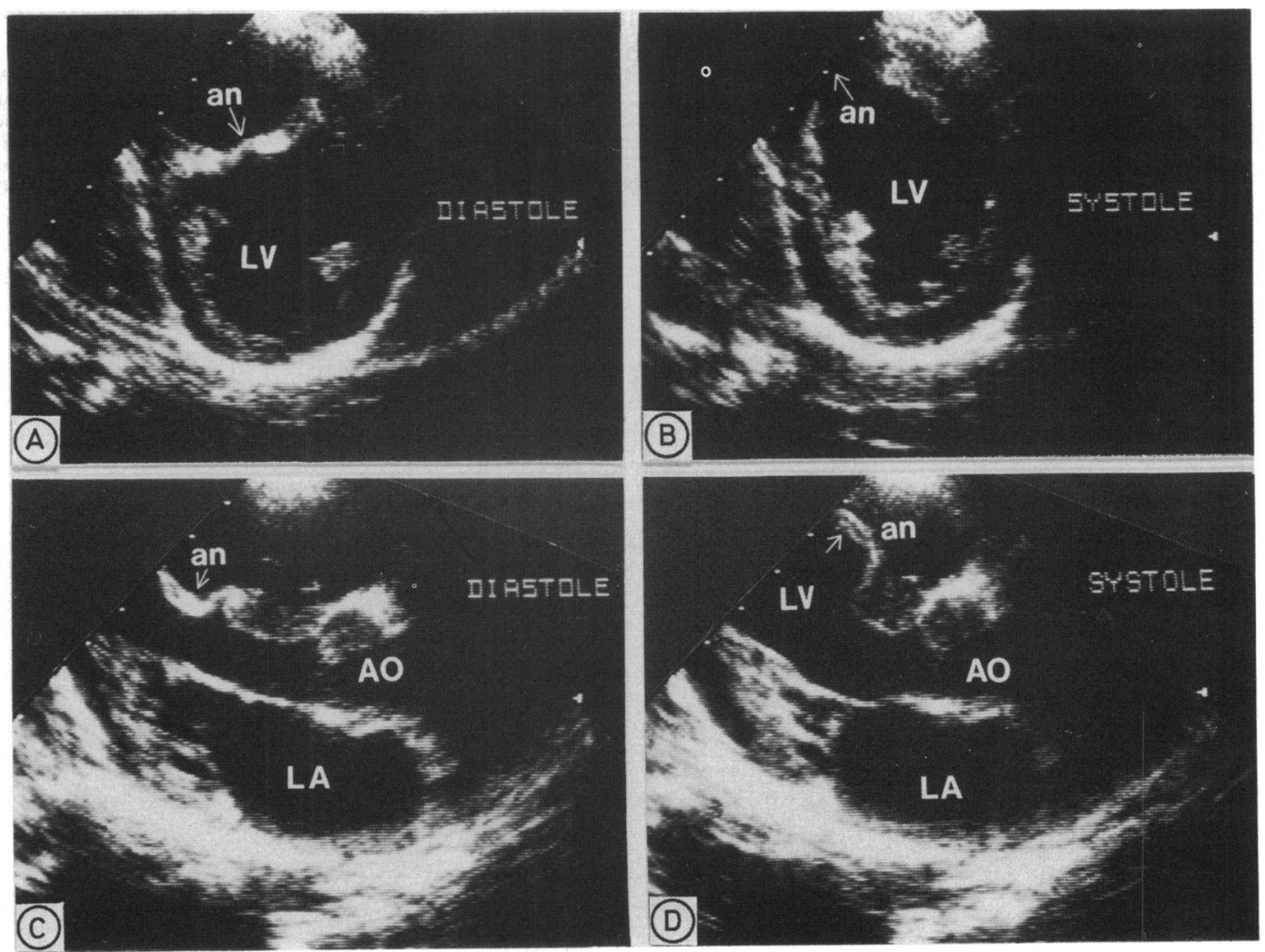

A four year old boy was referred for cardiac evaluation. He was symptom free, with no relevant past medical history. On examination he was pink with normal parasternal impulses and normal peripheral pulses. The first and

Department of Paediatric Cardiology, Royal Brompton and National Heart Hospital, London M-R Chen

M L Rigby

A N Redington

Correspondence to

Dr Andrew N Redington Department of Paediatric Cardiology, Royal Brompton and National Heart Hospital, Fulham Road, London SW3 $6 \mathrm{HP}$.

myocardial ischaemia of the newborn, blunt trauma to the chest, infection (syphilis, tuberculosis, rheumatic fever, mycosis, Chagas's disease, myocarditis), postoperative dosis, and Kawasaki disease. ${ }^{1}$ Congenital left ventricular aneurysm, which usually affects the annular subvalvar portion of the free wall or apex, is rare but well described. ${ }^{1-3}$ Congenare most unusual and only two cases have been reported. ${ }^{45}$ We report two further cases occurring in a father and his child. To our the ledge, familial, congenital aneurysm of been reported before.

\section{Case report}

Figure 1 Cross sectional echocardiogram from the four year old boy. There was gross systolic dyskinesis of the aneurysmal segment of the interventricular septum in the parasternal short axis ( $A$ and $B$ ) and long axis $(C$ and $D)$ sections. Note the clear demarcation between normal myocardium and the aneurysmal segment. $L V$, left ventricle; $L A$ left atrium; AO, aorta; an, aneurysm. 
Figure 2 Cross sectional echocardiograms from the father of the four year old boy. There was a similar aneurysmal area in the mid-muscular portion of the interventricular septum. The amplitude of dyskinetic motion of the aneurysmal segment was not as large as in his son (fig 1).
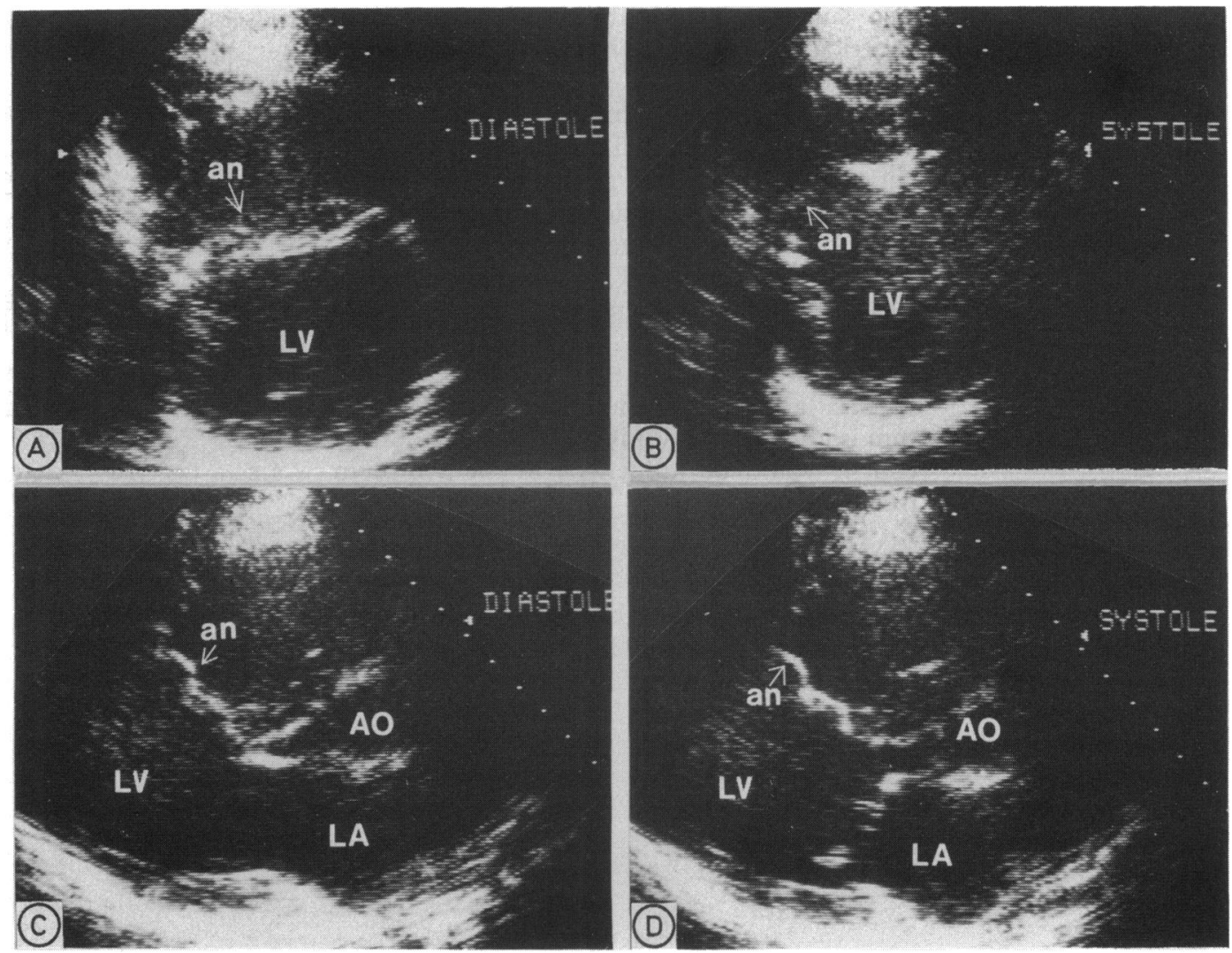

second heart sounds were normal but there was a loud mid-systolic ejection click. There were no murmurs, and no other abnormalities were detected.

Chest radiography was normal. The electrocardiogram showed sinus rhythm, with a mean frontal $Q R S$ axis of +20 and a normal adult precordial RS progression pattern. There were no $Q$ waves but the $T$ wave was inverted in V5 and biphasic in V6. Cross sectional echocardiography confirmed atrial situs solitus with normal atrioventricular and ventriculoarterial connections. There was a large area of paradoxical systolic motion in the midmuscular trabecular interventricular septum. The demarcation between myocardium and the aneurysmal segment was clear (fig 1). The phonocardiogram confirmed a systolic ejection click that did not coincide exactly with the anterior movement of the aneurysm recorded with $M$ mode echocardiography.

The child's father also underwent echocardiographic examination because of an earlier investigation for congenital heart disease. No previous records were available. He was 29 years old and symptom free. There was no relevant past history. The chest radiograph, electrocardiogram, and physical examination were normal. $M$ mode and cross sectional echocardiography showed a similar aneurysm in the mid-muscular part of the interventricular septum (fig 2). Again, there was obvious demarcation between the normal myocardium of the interventricular septum and the aneurysmal segment.

\section{Discussion}

This paper describes the familial occurrence of congenital aneurysms of the muscular interventricular septum. Only two cases of congenital aneurysm of the interventricular muscular septum have been reported before. In one, a 15 year old girl presenting with exertional dyspnoea, it was associated with a secundum atrial septal defect, a cleft mitral valve, and symptomatic ventricular tachycardia. ${ }^{4}$ There was extensive fibroelastosis of the right ventricle. This patient underwent surgery with suture of the mitral valve cleft and patch closure of the atrial septal defect. Aneurysmectomy was not considered possible. The other case was a symptom free 10 year old girl with clinical signs of a small ventricular septal defect. ${ }^{5}$ The electrocardiogram in this patient showed $Q$ waves in the septal leads. The aneurysm was shown by cross sectional echocardiography. Furthermore, there was rupture of the aneurysm in the mid-portion of the interventricular septum, accounting for the clinical signs of a ventricular septal defect. The echocardiographic appearances in our patients were remarkably similar to those reported before-with a large area of well demarcated aneurysmal interventricular muscular septum towards the apex of the left ventricle. Neither of our patients had fibroelastosis of the ventricles or rupture of the aneurysm.

The cause of these aneurysms is unknown. The familial occurrence in our patients may support the concept that they may result from an inherited embryological defect leading to weakness of the myocardium. ${ }^{6}$ We suggest that all first degree relatives of affected patients be screened by cross sectional echocardiography, particularly if there is an abnormal electrocardiogram. A systolic ejection click should 
also suggest the possibility of a congenital ventricular aneurysm, but is by no means a universal finding.

The course of congenital ventricular aneurysm is not known. In these patients, as with other congenital aneurysms, complications are likely to include rupture, arrhythmia, thromboembolism, and deteriorating ventricular function. ${ }^{36-8}$ The place for surgical treatment in these patients with uncomplicated lesions must remain uncertain, however. Surgical repair will be particularly difficult when a large part of the interventricular septum is affected, ${ }^{4}$ and it is not clear whether the course would be influenced in the symptom free patient.
1 Singh A, Katkov H, Zavoral JH, Sane SM, McLeod JD. Congenital aneurysms of the left ventricle. Am Heart 1980;99:25-32.

2 Treistman B, Cooley DA, Lufschanowski R, Leachman RD. Diverticulum or aneurysm of left ventricle. Am J Cardio 1973;32:119-23.

3 Arora RR, Issenberg HJ, Spindola-Franco H, Fayemi A, Steeg $\mathrm{C}$. Congenital aneurysm of the left ventricle. Its recognition and significance. JAMA 1988;259:3306-8.

4 Fasaoli G, Valentina PD, Scognamiglio R. Echocardiographic findings in left ventricular septal aneurysm. Int $J$ graphic findings in left
Cardiol 1988;18:441-3.

5 Magherini A, Schmidtlein C, Urciuolo A, et al. Congenital aneurysm of the interventricular muscular septum with rupture into the right ventricle in a child. Am Heart $J$ 1988;116:185-7.

6 Sawyer AJ, Mauss IH, Rosenblatt P. Congenital diverticulosis of left ventricle. Am J Dis Child 1950;79:111-7.

7 Franco-Vazques S, Sutherland RD, Fowler M, Edwards JE Congenital aneurysm of left ventricle base. Chest 1970; 57:411-5.

8 Burn CG, Hollander AG, Crawford JH. Rare cardiac aneurysm in a child. Am Heart $J 1943 ; 26: 415-8$. 